\title{
Sofrimento e Adoecimento dos Vendedores de uma Empresa de Material de Construção
}

\author{
Carla Sabrina Antloga ${ }^{1}$ \\ Ana Magnólia Mendes \\ Universidade de Brasília
}

\begin{abstract}
RESUMO - Este estudo investigou o prazer e o sofrimento dos vendedores de uma empresa de material de construção, utilizando a abordagem da psicodinâmica do trabalho. Prazer refere-se a vivências de realização profissional e liberdade de expressão; sofrimento, por outro lado, refere-se a vivências de esgotamento emocional e de falta de reconhecimento. O sofrimento, quando vivenciado, é mediado por estratégias defensivas, de compensação e de mobilização subjetiva. No presente estudo foram realizadas entrevistas coletivas semi-estruturadas com dois grupos de sete vendedores, as quais foram posteriormente submetidas à análise de conteúdo categorial temática. As categorias resultantes foram "ressentimentos”, "pressão no trabalho”, "cansaço", "ambiguidade na relação com a chefia", "medo" e "desconfiança”. Com base nas categorias resultantes, identificase o predomínio do sofrimento em função das pressões, da sobrecarga e da ausência de espaço para falar sobre o trabalho. As estratégias defensivas utilizadas pelos trabalhadores, entretanto, não têm sido suficientes para protegê-los do adoecimento físico e mental. Conclui-se o estudo com recomendações para a empresa e sugestões de novas pesquisas.
\end{abstract}

Palavras chave: psicodinâmica do trabalho; prazer-sofrimento; vendedores de material de construção.

\section{Suffering and Illness of the Sellers of a Construction Material Company}

\begin{abstract}
This study investigated pleasure and suffering of the sellers of a construction material company using the approach of psychodynamic of work. Pleasure consists of professional experience achievement and freedom of speech. Suffering refers, on the other hand, to emotional exhaustion and lack of recognition. During suffering experiences, it is possible to identify defensive, compensational and subjective mobilization strategies. In this study, collective semi-structured interviews were conducted with two groups of seven sellers each. After that, the interviews were submitted to a thematic categorical content analysis. The results pointed out that the categories were "resentment”, "pressure at work", "tiredness", "ambiguity in the relationship with their bosses", "fear" and "distrust”. Based on the resulting categories, it is possible to identify the prevalence of suffering at work related to the pressure, the overload and the lack of freedom to speak about the work. The defensive strategies applied by the sellers, however, have not been enough to protect them from mental and physics illness. This study is concluded with some recommendations to the company and suggestions of new studies.
\end{abstract}

Keywords: psychodynamic of work; pleasure-suffering; construction material sellers.

O trabalho pode assumir diversos sentidos para os trabalhadores: ser um modo peculiar e singular de produzir, de realizar-se, de sobreviver e de estruturar-se psiquicamente. Esses sentidos são atribuídos com base na relação que o trabalhador estabelece com os modos de produção que oferecem condições e oportunidades específicas. Assim, esses sentidos, a depender de cada contexto de trabalho, podem ter como resultados vivências de prazer e de sofrimento.

Historicamente pode ser observada uma evolução nos modos de se executar o trabalho. Antunes (1998) traça um perfil cronológico dessas estruturas e como se deram as modificações ao longo do século XX. Segundo o autor, pode-se considerar que o primeiro sistema de produção estruturado foi o taylorismo. Baseado nos princípios de homogeneidade, verticalização, fragmentação, mecanização e repetitividade,

1 Endereço para correspondência: SQN 405 Bloco H Ap. 302. Brasília, DF. CEP 70.846-080.E-mail: antloga@yahoo.com esse sistema de trabalho subjugava as atividades intelectuais e o "saber fazer", de forma que o trabalhador não se identificava com suas tarefas.

Contemporâneo ao taylorismo tem-se o fordismo, baseado em princípios semelhantes, destacando-se o valor dado à produção em série e à execução de tarefas também seccionadas, que levariam a um produto padronizado. Houve, durante este período, um controle total sobre os movimentos dos trabalhadores. Seus eventos psíquicos, se conhecidos, eram desconsiderados.

Nos anos 60, o binômio taylorismo-fordismo entra em declínio. Os operários, antes dominados e controlados, passam a reagir de forma consistente e organizada. Antunes (2000) ressalta que formas individuais e coletivas de ação manifestam-se, indo desde o absenteísmo até as greves parciais e “operação do zelo", estratégia coletiva dos trabalhadores, que operam adotando uma política de cuidado máximo e preservação extrema do material de trabalho, o que leva à lentificação e atraso na produção. Segundo o autor, no início 
dos anos 70 há uma reestruturação total, embora o capitalismo, renovado, continue a ser o sistema vigente no mundo. Ocorre uma recuperação do ciclo reprodutivo e também da dominação societal imposta pelo sistema capitalista.

Posterior à referida reformulação do capitalismo, o toyotismo, ou modelo japonês, é estruturado. Esse modelo pressupõe trabalho em equipe, maior número de tarefas em um menor espaço de tempo, numa empresa "enxuta", com um quadro de funcionários reduzido e gastos baixos. Iniciam-se então, os processos de terceirização, nos quais o trabalhador recebe para, entre outras coisas, pensar para a empresa.

Todos esses processos tiveram, e ainda têm, implicações diretas no significado do trabalho, e por consequência, no sentido que ele tem para o indivíduo. Morin (2002) defende que um trabalho é percebido como significativo quando é realizado de maneira eficiente, levando a um resultado útil; quando é satisfatório; quando proporciona relações socioprofissionais saudáveis e, ademais, garante segurança, autonomia e ocupação efetiva do tempo.

Acredita-se, por isso, que, atualmente, o trabalho revive, em várias formas, o tão criticado taylorismo. Pode-se afirmar que encontrar sentido no trabalho, o que seria fonte de realização e de vivências de prazer (Mendes, 2007; Morin, 2002), tem sido cada vez mais complicado e difícil.

Não se pode ignorar também o fato da globalização estar acompanhada por mudanças agudas, que transformam o ambiente de maneira correspondente. Para questões complexas de trabalho são necessárias soluções rápidas, precisas, que mantenham as organizações e os trabalhadores num circuito de competição acirrada.

Frente a esse panorama, o trabalhador experimenta os mais diversos tipos de sensações e vivências. Questões amplas surgem: como esse sujeito enfrenta as situações adversas? Quais são os sentimentos mais frequentes e quais são as formas utilizadas para lidar com isto? Como pensa as questões ocorridas no ambiente que ocupa grande parte de sua vida?

Buscando responder a essas questões, a psicodinâmica do trabalho vem tradicionalmente estudando as vivências de prazer e sofrimento do trabalhador, relacionadas à organização do trabalho. Essa abordagem tem origem e desenvolvimento nos estudos de Dejours (1987, 1993a, 1987/1993b, 1998/1999b, 1999/1999c, 2001a, 2001c) e vem avançando com os estudos de Mendes (1994, 1995, 1996, 2004, 2007). Observam-se três fases distintas da psicodinâmica.

A primeira contempla os trabalhos desenvolvidos na década de 80 , fundamentados no estudo do sofrimento psíquico, bem como sua origem e transformações resultantes do confronto entre psiquismo do trabalhador e organização do trabalho. Nessa fase, são estudadas a dinâmica do sofrimento e as estratégias defensivas desenvolvidas frente ao sofrimento.

A segunda fase inicia a abordagem do prazer no trabalho e, consequentemente, tem-se um direcionamento para a saúde. Os estudos que anteriormente se pautavam somente em sentimentos de sofrimento tentam agora identificar de que forma o trabalhador pode vivenciar uma realidade prazerosa, na qual exista um trabalho saudável. Essa etapa permanece até o início da década de 90.
O desenvolvimento da terceira etapa acontece mediante o enfoque no trabalho como locus de construção da identidade do trabalhador. Estuda-se também a dinâmica do reconhecimento e as vivências de prazer e sofrimento frente às novas estruturas de organização do trabalho.

Para a psicodinâmica, o trabalho é o espaço no qual o sujeito pode realizar suas motivações e desejos, formados em função de sua história de vida e relacionados à sua estrutura de personalidade. Assim, esse sujeito interpreta a realidade de trabalho, não sendo de forma alguma indiferente a ela, reagindo física, mental e afetivamente. Por outro lado, a realidade produz alterações no sujeito, resultando em um processo no qual a realidade psíquica e a realidade de trabalho constituem a subjetividade desse trabalhador, sendo esta tratada como construção articulada entre o psíquico e o social.

O trabalho, especificamente, é visto como o lugar de descarga psíquica da energia do trabalhador. Embora essa energia já esteja fluindo no campo social, por meio de processos sublimatórios, há também no trabalho um caminho para ela, e é por esse caminho que o sujeito reconhece sua identidade, por meio do fazer. O trabalho torna-se, assim, um meio para satisfações concretas e simbólicas.

Por satisfações concretas tomam-se aquelas referentes à proteção da vida, ao bem-estar físico, biológico, nervoso, ou seja, a saúde do corpo do indivíduo. Simbolicamente, as satisfações relacionam-se à realização do trabalhador, por atribuir significado ao seu trabalho.

Em relação à saúde do trabalhador, esta é compreendida como um estado de conquista e de construção, na medida em que o trabalhador se depara com uma realidade nem sempre adequada às suas perspectivas e necessidades. Esses trabalhadores, dotados de uma dinâmica subjetiva, sujeita aos impactos do trabalho, têm também fragilidades psíquicas e somáticas, que podem favorecer, ou não, a saúde psíquica no contexto de trabalho.

O sofrimento é, dessa forma, o resultado de conflitos intersubjetivos e intra-subjetivos dos trabalhadores com a realidade de trabalho. Prazer e sofrimento são, para essa abordagem, conceitos inerentes ao trabalho, relacionados ao fluxo do processo psíquico do indivíduo, que é determinado pela realização ou repressão da energia psíquica na relação indivíduo-trabalho.

Segundo o modelo teórico, todo trabalho pressupõe uma carga psíquica, que é o resultado da confrontação do desejo do trabalhador com a realidade da organização do trabalho. A carga psíquica resulta, também, da pressão atribuída pela organização do trabalho ao aparelho psíquico do trabalhador. Quando o trabalho permite a redução da carga psíquica e um funcionamento livre do psiquismo, torna-se fonte de gratificação, que é origem de prazer. Entretanto, quando o trabalho não oferece espaço para articulações entre os desejos do trabalhador e a realidade, resulta em acúmulo ou bloqueio da energia psíquica, tornando-se fonte de tensão e sofrimento.

Em decorrência do sofrimento no trabalho podem ser desenvolvidas, pelo trabalhador, estratégias de enfrentamento, podendo ser defensivas ou de mobilização subjetiva. Essas estratégias são responsáveis por evitar o adoecimento no trabalho, sendo que esse acontece quando falham estratégias 
para lidar com o sofrimento e quando o trabalhador não tem oportunidade de mudar a organização do trabalho.

As estratégias defensivas são mecanismos utilizados pelos trabalhadores para evitar ou minimizar a percepção de uma realidade de sofrimento (Dejours \& Abdoucheli, 1990), e apresentam especificidades que variam para cada categoria profissional. Estudos nessa abordagem (Dejours, Abdoucheli \& Jayet, 1994; Mendes \& Morrone, 2002) indicam comportamento de isolamento psicoafetivo e profissional do grupo de trabalho, resignação, descrença, renúncia à participação, indiferença e apatia como comportamentos comuns em trabalhadores que adotam esse caminho. As defesas são utilizadas, também, quando há um fracasso nas tentativas de negociação com a empresa e com a chefia, evitando o aspecto doloroso da realidade de trabalho e mantendo o equilíbrio psíquico.

Jayet (1994) aponta alguns indicadores de utilização de estratégias defensivas no trabalho: desmotivação e desencorajamento; condutas de evitação, por exemplo, absenteísmo; comportamentos agressivos de violência ou rebelião; diluição das responsabilidades, isto é, o trabalhador evita riscos e desafios; ativismo, ou seja, um envolvimento em diversas situações, simultaneamente, evitando a consciência de situações desconfortáveis; presença excessiva no local de trabalho, fora do expediente; individualismo caracterizado pela realização das tarefas de forma autônoma, pelos rompantes de agressividade, pela dispersão das formas de convivência e pela excessiva competição.

Em alguns casos, a utilização dessas estratégias defensivas pode ter uma função positiva, colaborando para o equilíbrio psíquico e favorecendo a adaptação às situações de desgaste emocional pelo confronto permanente do profissional com situações emocionalmente difíceis, como relatam Linhares (1994) e Mendes e Linhares (1996). Entretanto, a utilização dessas estratégias pode mascarar o sofrimento psíquico, se provocar uma estabilidade psíquica artificial. Nesses casos, a defesa assume uma dimensão patológica, interferindo no trabalho e na vida social dos trabalhadores.

Embora haja um lado positivo na utilização das defesas, observa-se que há um papel contraditório em sua utilização. Se as mesmas são necessárias para manter o equilíbrio psíquico, podem, por outro lado, levar a processos como imobilismo e alienação, significando que a melhor estratégia é a busca do prazer no trabalho, por meio da mobilização subjetiva. Essa atitude permite ao trabalhador afirmar-se enquanto sujeito, reforçando sua identidade pessoal e profissional.

A mobilização subjetiva é o processo que permite ao trabalhador transformar o sofrimento em prazer, por meio do resgate do sentido do trabalho. Por sentido do trabalho entende-se, segundo Morrone (2001), a relação entre a subjetividade do trabalhador, o saber fazer e o coletivo de trabalho.

A subjetividade do trabalhador corresponde à relação desenvolvida entre o psíquico e o social. É a forma de o trabalhador dar sentido ao trabalho, quando confrontado com certa realidade (1997/1999a).

Saber fazer, ou savoir-faire, como descrito por Dejours (1997/1999a), é um tipo de inteligência prática, que auxilia o trabalhador a regular as diferenças entre o trabalho prescrito e o trabalho real, possibilitando o desenvolvimento de um modo próprio de realização do trabalho, mesmo que não haja domínio da tecnologia, pressupostamente necessário.

Coletivo de trabalho é a denominação de uma situação existente, independentemente da vontade da empresa, caracterizada pelo relacionamento saudável entre os trabalhadores. Essa situação é construída de acordo com regras técnicas e de comportamento, pautadas em uma dimensão ética que reflete valores, julgamento de estética e qualidade do trabalho. A cooperação também é importante para o coletivo de trabalho. Na verdade, a cooperação é uma condição para o estabelecimento desse coletivo, já que permite a visibilidade de ações, confiança, discussão, consenso, deliberação, arbitragem, participação nas decisões, construção de acordos e de regras de trabalho, ação pública e política, com a finalidade de gerir a organização do trabalho (Mendes, 1996).

Com base nessas referências, o presente estudo tem por objetivo descrever a psicodinâmica do trabalho dos vendedores de uma empresa de material de construção, por meio da análise das vivências de prazer e de sofrimento.

A empresa em questão é caracterizada como sendo de médio porte e situa-se em Brasília-DF. Com base no planejamento estratégico da organização, pode-se depreender algumas informações úteis para a caracterização do contexto da empresa.

A empresa é caracterizada por ser uma loja de varejo arrojada, procurando atender o maior número possível de clientes e, assim, gerar uma alta rotatividade de estoques e de capital. Esse modelo de trabalho assemelha-se às discount shops (lojas de desconto) americanas. Enquadrando-se nesse modelo, a empresa não se limita a atender uma categoria específica de clientes, buscando, outrossim, oferecer produtos a preços competitivos, com uma prestação de serviços técnica, pessoal, simples e direta.

As principais diretrizes da empresa são: comprar qualitativamente a preços baixos; vender volumes crescentes, agregados à prestação de serviços; aumentar as margens de rentabilidade; reduzir os custos e as despesas. A saída do produto se dá exclusivamente pelo processo de venda, que pode ser tratado como de auto-serviço (self-service), quando o cliente retira a mercadoria nas prateleiras e passa no caixa; serviço tradicional, com o cliente se dirigindo a um vendedor e retirando as mercadorias no serviço de expedição do depósito; e entrega em domicílio, quando o cliente especifica o endereço para onde o material deve ser despachado.

A empresa pode ser categorizada como uma empresa familiar, tanto pela forma de administração, baseada em confiança e relações de amizade, como pela presença de familiares na gestão, critérios propostos por Rebouças de Oliveira (1999) para caracterizar uma organização como familiar. No momento desta pesquisa, pai e filho dividiam a administração do negócio. Um outro ponto a ser ressaltado refere-se a um momento crítico enfrentado pela empresa e pelos trabalhadores: alguns anos antes da coleta de dados para este estudo, a empresa entrou com pedido de concordata, para evitar a falência do negócio.

Para atingir o objetivo proposto, realizou-se uma pesquisa qualitativa, como descrita a seguir. 


\section{Método}

\section{Participantes}

Participaram da pesquisa 14 vendedores, selecionados randomicamente entre 85 vendedores.

\section{Instrumentos}

A coleta de dados realizou-se com a utilização de duas entrevistas coletivas semi-estruturadas. Dois eixos principais nortearam o roteiro de entrevistas.

O primeiro eixo, referente à organização do trabalho, conteve perguntas sobre a atividade, envolvendo o conteúdo das tarefas, processo de trabalho, pressões, controle, horário de expediente e pausas, além de relações sócio-profissionais com colegas e chefia. A pergunta principal desse eixo foi "o que você faz em um dia típico de seu trabalho?”, seguida por “como são suas relações com seus colegas e superiores?”.

O segundo eixo, referente aos sentimentos no trabalho, conteve perguntas para investigar como os funcionários se sentiam executando o trabalho, convivendo com os colegas e com a chefia, e no caso de haver sentimentos negativos, como lidavam com eles. As principais perguntas desse eixo foram “como você se sente em seu trabalho?" e "como você lida com estes sentimentos?”.

\section{Procedimento}

O contato com a empresa participante da pesquisa se deu em função de uma demanda, para uma das pesquisadoras, de pesquisa de clima organizacional. Essa demanda foi aceita, com a condição de que houvesse autorização para a realização do estudo sobre sofrimento no trabalho, especificamente. Assim, o proprietário da empresa concedeu autorização para as entrevistas. Por meio de lista fornecida pelo departamento de pessoal, os funcionários foram numerados de 01 a 85 . Realizou-se um sorteio, utilizando-se uma lista de números randômicos. Foram sorteados 14 vendedores.

Como a direção da empresa permitiu a realização das entrevistas em horário de expediente, foi acordado com o gerente do setor o dia e o horário mais conveniente para a realização das mesmas. Foi disponibilizado pela empresa o espaço da sala de treinamento. Todas as entrevistas coletivas foram realizadas por duas pesquisadoras. Para iniciar as entrevistas, havia a apresentação das entrevistadoras, explicação de que o conteúdo da entrevista era sigiloso e breve apresentação do roteiro. Explicitou-se a necessidade de gravação em áudio, por questões metodológicas. Salientou-se, nesse momento, o caráter voluntário da participação, sendo confirmada a vontade dos participantes de se submeterem à entrevista. Nenhum funcionário desistiu de participar.

As entrevistas transcorreram sem interrupções, e tiveram duração média de 1 hora e 10 minutos.

Não foi possível realizar validação dos dados junto aos participantes, por indisponibilidade dos mesmos. A devolução dos dados se deu 60 dias após a realização da última entrevista. Entrou-se em contato com os participantes, os quais foram notificados que em determinados dia e períodos haveria uma pesquisadora apresentando os resultados da pesquisa. Apresentaram-se cinco participantes, aos quais foram passadas as categorias das entrevistas, e comentada a teoria que sustentava o estudo, bem como as recomendações que seriam passadas para a empresa.

Foram encaminhados para a empresa um relatório executivo, com um breve apanhado teórico, as categorias resultantes das entrevistas e recomendações. A gerência da empresa não se mostrou disposta a comentar o relatório, de forma que desejou, somente, recebê-lo via e-mail.

\section{Análise dos dados}

As entrevistas foram submetidas à análise de conteúdo categorial temática. A análise de conteúdo é fundamentada nos estudos de Bardin (1977). Para esta autora, a comunicação é um processo que tem a palavra como mediadora do sentido. O discurso é um processo de elaboração, onde estão presentes motivações, desejos e investimentos do indivíduo.

Para a análise categorial temática utiliza-se o critério de recorrência de temas, que passam por uma contagem de frequência. Temas recorrentes são classificados em categorias específicas e depois ajustados em categorias gerais. Cada uma das entrevistas foi submetida à análise de dois juízes, que definiram as categorias específicas, determinadas sobre os conteúdos predominantes nas verbalizações ocorridas nas entrevistas.

\section{Resultados}

\section{O trabalho dos vendedores e suas vivências de sofrimento}

Nesta seção, apresentam-se as categorias empíricas resultantes das entrevistas coletivas com os vendedores. Observa-se que a organização do trabalho permeia o conteúdo de todas as categorias, e que se relaciona ao sofrimento evidenciado em cada uma delas.

Categoria 1: Ressentimentos. Os vendedores sentem mágoa por não serem reconhecidos, nem mesmo pelo fato de terem contribuído para que a empresa não fosse à falência, aceitando cortes nas comissões e enfrentando o medo de demissão. Há humilhação, revolta e indignação, atribuídas, entre outros, ao comportamento "hipócrita" da gerência, que às vezes xinga os funcionários, embora ratifique a necessidade de se ter um bom ambiente de trabalho. Sentem-se desanimados, acham que nada vai mudar, pois o dono veta novidades e ideias que poderiam amenizar a situação.

Categoria 2: Pressão no trabalho. A pressão existe por parte da empresa e dos funcionários em relação ao próprio trabalho. A empresa pressiona para que se venda cada vez mais e para que não haja erro nos procedimentos burocráticos de venda, como emissão de notas. Os funcionários se pressionam para cobrir a cota de vendas, que aumentou significativamente. Medo, desespero, insônia, ansiedade, tonturas, 
sensação de sufocamento e vontade de não ir para o trabalho decorrem desse contexto, bem como o questionamento sobre a própria saúde mental. A maioria das pessoas que passa pela loja não aguenta o sistema e sai do emprego.

Categoria 3: Cansaço. O dia de trabalho é considerado cansativo. Não há horário fixo para término do expediente e os funcionários têm que ficar na loja até o cliente ir embora. Trabalham nos finais de semana e feriados, o que ocasiona esgotamento físico e mental, desencadeando problemas como dores de cabeça, tonturas, desmaios e dores no corpo. Além disso, sentem culpa por perceber que as relações sociais e familiares são prejudicadas pela extensa jornada.

Categoria 4: Ambiguidade na relação com a chefia. Os chefes falam de proximidade, mas comportam-se com distanciamento. Há pessoas que são “intocáveis” na gerência, e que, por não serem passíveis de punições, podem se comportar de maneira a humilhar, pressionar e punir os trabalhadores ilimitadamente. Os funcionários ficam confusos e desmotivados, pois se emitem uma opinião, são punidos; se não a emitem, também.

Categoria 5: Medo. Os funcionários sentem medo de errar, de emitir opiniões, medo da "fofoca" de colegas, de não atingir a cota de vendas e de serem demitidos. Também sentem medo da chefia e do modo de funcionamento da loja, que impõe castigos, num sistema "terrorista".

Categoria 6: Desconfiança. Os funcionários sentem que a relação com os colegas foi prejudicada pela necessidade de vender mais, decorrente da concordata. Embora ainda haja colegas companheiros, não sabem em quem confiar, há muitos "dedos duros" a serviço da chefia, e muitos têm estado com o "pé atrás” com os colegas.

Na Categoria 1, o sofrimento aparece relacionado aos ressentimentos frente a uma chefia que não reconhece o trabalho dos funcionários, e que se comporta de forma hipócrita e estagnada, não permitindo mudanças. Além disso, os funcionários sentem humilhação, revolta e indignação pelo comportamento contraditório da chefia. Há sofrimento, ainda, ligado ao desânimo frente a uma situação percebida como cristalizada dentro da empresa.

Na Categoria 2, o sentimento de pressão no trabalho relaciona-se ao sofrimento, porque os funcionários sentem medo, desespero, ansiedade e outros sentimentos negativos, por temerem não atender as exigências da empresa. Esses funcionários têm problemas recorrentes de tonturas e desmaios, e a organização, embora saiba dessas ocorrências, não toma qualquer providência para compreender o que se passa. Os empregados seguem trabalhando, suportando o cansaço e o esgotamento, tanto físico como mental, inclusive pela necessidade de manter o emprego.

$\mathrm{Na}$ Categoria 3, o sofrimento relaciona-se à extensa jornada de trabalho, que ocasiona esgotamento físico e mental e interfere nas relações sociais e familiares dos funcionários.

O sofrimento na Categoria 4 aparece em decorrência da confusão e desmotivação que os funcionários sentem por terem que lidar com uma chefia que se comporta de forma ambígua frente às opiniões dos funcionários, e que é percebida como sinônimo de pressão, punição e humilhação. Além disso, o comportamento paradoxal de falar em proximidade e se comportar com distanciamento, também é recebido com desconforto pelos funcionários.
Na Categoria 5, o sofrimento é o próprio medo de emitirem opiniões, de errarem, de serem demitidos e de não atenderem à cota de vendas imposta pela empresa.

Observa-se, na Categoria 6, um sentimento de desconfiança em relação aos colegas, por não saberem em quem podem confiar, o que leva a uma dificuldade de relacionamento autêntico e transparente, impossibilitando também a cooperação.

\section{Discussão}

\section{Como enfrentar o sofrimento no trabalho de vendas?}

Para discutir os resultados, retoma-se aqui o objetivo deste estudo: descrever a psicodinâmica do trabalho dos vendedores, por meio da análise das vivências de prazer e sofrimento. Serão privilegiados, em função disso, o sentido do trabalho para os vendedores, as estratégias defensivas e/ou de mobilização e as referências a adoecimento. Junto a isso, focam-se as questões de coletivo de trabalho, de subjetividade dos trabalhadores e de possibilidades para a empresa e para a organização do trabalho.

Entender que sua atividade é importante e tem sentido é, para qualquer trabalhador, fonte de satisfação e de prazer. Por outro lado, experimentar sensações desagradáveis a maior parte do tempo, ter que lidar com medo, ressentimento, cansaço, desconfiança e pressão, sem poder, muitas vezes, sequer falar sobre os temas, leva o trabalhador a experimentar sofrimento, desgaste e desgosto pelo que faz.

Como defendido por Morrone (2001), o sentido do trabalho vem da relação entre a subjetividade do trabalhador, o saber fazer e o coletivo de trabalho. Para os vendedores participantes da presente pesquisa, tanto o saber fazer quanto o coletivo de trabalho apresentam-se sufocados pela organização do trabalho e pelas estratégias organizacionais. Pode-se supor que a construção de sua subjetividade de trabalhador esteja marcada, e inclusive dificultada por esse estrangulamento nas relações e no fazer.

Antunes $(1998,2000)$ aponta que a falta de sentido no que se faz é estratégia contemporânea para privar o trabalhador de uma identificação maior com o seu trabalho, com sua categoria profissional e com seus colegas. As dificuldades encontradas para falar das angústias enfraquecem ainda mais o já frágil coletivo de trabalho e tendem a promover o isolamento do trabalhador (como ratificado pela categoria "Desconfiança"), facilitando, do ponto de vista da organização, a adoção de estratégias mais duras, punitivas e perversas. É um ciclo retroalimentado - quanto mais isolado está o trabalhador, mais suscetível às pressões ele fica; quanto mais pressionado é, mais ele sofre; quanto mais sofre, menos sentido seu trabalho faz.

Evidencia-se, aqui, um paradoxo: embora o sofrimento esteja relacionado à organização do trabalho, em função das estratégias adotadas pela organização que levam ao desmantelamento do coletivo, o trabalhador parece ser o único responsável pelo que sente. Por razões óbvias, que incluem o medo e a desconfiança, os vendedores não expõem 
suas vivências e seus sentimentos, tendo que enfrentá-los sozinhos.

Também para Mendes e Morrone (2002), a formação do coletivo parte da possibilidade de discussão sobre as vivências no trabalho. Quando esse coletivo está estruturado, os funcionários têm mais estratégias e possibilidades para lidar com o sofrimento. Quando não, dificulta-se a construção da subjetividade, levando o trabalhador a não se compreender como sujeito do que faz, e desencadeando, por consequência, sofrimento no trabalho.

Ainda sobre sofrimento, Dejours (2001b) afirma que pior que vivenciá-lo é se sentir covarde por não se defender, por não haver coragem para se revoltar. $\mathrm{O}$ autor coloca essa situação como o cúmulo do sofrimento, onde o sujeito acredita ser responsável por toda a situação, enquanto somente representa um papel. No caso dos vendedores, o papel que representam é o de trabalhadores que aguentam a pressão, o cansaço e o medo, sendo que, como se percebe nas categorias das entrevistas, eles estão cada vez mais vulneráveis, com dificuldades no trabalho e adoecendo.

Outra questão referente ao coletivo de trabalho é que quando, na empresa, os trabalhadores não conseguem falar sobre como se sentem, passam a pensar que estão enlouquecendo. Isso se agrava em função da grande quantidade de tarefas, o que não permite que os empregados se dêem conta de que boa parte dos colegas passa pela mesma situação. Ou seja, em função da dificuldade de estabelecer regras de convivência, devido à extensa jornada, há pouco entrosamento entre eles, e, consequentemente, pouca possibilidade de apoio emocional. Sentem-se, então, sozinhos e confusos.

Para a psicodinâmica do trabalho, o sofrimento pode ser evitado por meio das defesas, trabalhado por meio da mobilização, ou ainda pode levar ao adoecimento. No caso desses vendedores, defesas estão explicitadas nas categorias "medo" e "desconfiança". Entretanto, parece que tais defesas apresentam sinais de falhas. Essas falhas se evidenciam no adoecimento evidenciado nas categorias "pressão no trabalho" e "cansaço", quando os trabalhadores fazem referência a desespero, insônia, ansiedade, tonturas, sensação de sufocamento, esgotamento físico e mental, dores de cabeça, desmaios. Estes sintomas são sinais de adoecimento físico e mental.

A mobilização subjetiva tão pouco pode ser desenvolvida nesse contexto. Para mobilizar-se subjetivamente o trabalhador precisa do coletivo, que, como já discutido, não pode ser construído. Reforça-se, então, a tese de que o caminho mais provável é o do adoecimento, inclusive se for somado ao fato de que também a relação com a família está prejudicada, pois não sobra tempo. As relações interpessoais externas ao trabalho, que poderiam ser fonte de alívio, sequer podem ser vividas. Não há situação na qual extravasar ou elaborar os conteúdos vivenciados.

Nesse sentido, o adoecimento pode também ser um dos reflexos do sofrimento não só negligenciado, mas principalmente, calado. Dejours (1997/1999a) defende que o sofrimento, quando não encontra via para ser elaborado, como no caso da fala compartilhada, tende a se transformar em adoecimento, e é comum que sintomas semelhantes se apresentem para uma mesma categoria, como no caso dos vendedores, que sofrem com ansiedade, insônia, tonturas, entre outros.

Sobre a categoria “medo”, traz-se o comentário de Enriquez (2000), que afirma que os trabalhadores experimentam esse sentimento quando não compreendem bem o que fazer, nem como se comportar. No caso dos vendedores, há o medo de advertências, de emitir opiniões e até de serem demitidos. Embora apareça, no presente estudo, como estratégia de defesa, esse sentimento tende a levar o trabalhador ao adoecimento; é, nesse caso, uma defesa em via de falência. Igualmente, o medo provoca o oposto do desejado pela empresa: os trabalhadores gastam muito tempo preocupados, tensos e ansiosos, o que, evidentemente, prejudica a produtividade.

O cansaço devido ao ritmo de trabalho intenso reflete-se em queixas sobre dores de cabeça, dores musculares e dificuldade em se desligar do trabalho. Há, ainda, a percepção da empresa como uma organização hermética, não possibilitando a expressão de idéias e nem espaço para sentimentos, levando a uma dificuldade de identificação do trabalhador com sua atividade. Segundo Ferreira e Mendes (2001) e Mendes e Morrone (2002), essa dificuldade de identificação é um dos aspectos da gênese do sofrimento no trabalho. Impossibilitado de expressar sua individualidade na tarefa e no processo de trabalho, o funcionário experimenta sentimentos de descontentamento e desânimo, sofrendo, o seu trabalho, interferências diretas.

As categorias “Ressentimentos”, “Ambiguidade na relação com a chefia", "Medo" e "Desconfiança" configuram-se permeadas por aspectos que remetem a constrangimento e controle. Para Dejours (2001d), em diversas situações as empresas fazem questão de promover o clima de pressão e humilhação, como forma de reforçar o individualismo, em detrimento da cooperação e da colaboração. No caso desses vendedores, o estímulo à individualidade é percebido quando se focam as contradições: a empresa ratifica a necessidade de um bom ambiente de trabalho, mas, na prática, confunde os funcionários sobre a importância de expressar opiniões, mantém a cota de vendas individualizada e impões castigos. Além de, novamente, impossibilitar a construção do coletivo de trabalho, reforça-se um estado de "cada um por si".

Em relação à empresa, pode-se remeter ao mesmo Dejours (2001d), quando afirma que relações interpessoais frágeis tendem a comprometer o futuro das organizações. Isso porque as regras de trabalho não são fundamentadas somente em uma dimensão técnica ou em critérios de eficácia, mas principalmente sobre o saber fazer, que na maioria das vezes é coletivo. O autor defende que quando não há espaço para a convivência, para deliberação e discussão dentro do trabalho, a organização do trabalho torna-se esclerosada, não evolui e prejudica a empresa.

Como empresa familiar que é, a presente organização tem, entre seus gerentes, o pai, dono da empresa, e o filho, gerente de produtos. As decisões são centralizadas basicamente nessas duas pessoas, e os trabalhadores são raramente ouvidos (quando ouvidos, geralmente têm suas idéias ignoradas). Estudos realizados em empresas familiares (Bernhoeft, 1999; Montgomery \& Amaral, 1999) relatam que essa estrutura é típica na maioria das empresas desse tipo, com o pai assumindo o posto de maior controle, seguido de perto por um 
dos membros da família. Assim, os vendedores, que são os responsáveis pela geração do capital para a organização, são pouco ou nunca ouvidos, mesmo porque têm medo de se expressar. A empresa perde informações preciosas, pois os trabalhadores, ao invés de estarem próximas dela, acabam se afastando, por seus sentimentos de medo e desconfiança.

Os vendedores não se sentem valorizados por sua contribuição para a empresa, doando tempo além do estabelecido em contrato e trabalhando constantemente sob pressão, sem nenhum reconhecimento. Evidentemente, há aspectos de cunho econômico que interferem nesse processo, dado que muitas vezes as empresas alegam que não estão em boas condições financeiras para melhorar salários ou comissões. Entretanto, pode-se questionar se uma melhoria no tratamento dispensado aos trabalhadores não poderia refletir em pessoas mais saudáveis e felizes com suas atividades, resultando em melhor produtividade, como defendem Derrienic e Vézina (2000). Os autores fazem um dossiê sobre estudos epidemiológicos acerca de sofrimento psíquico no trabalho e comentam sobre o aumento significativo de queixas de problemas psicológicos nas empresas, reflexo do descuido com os funcionários e elemento explicador das reclamações de improdutividade feitas por superiores.

Em suma, com o predomínio do sofrimento no trabalho e com a dificuldade de construção de mobilização subjetiva e de utilização de defesas, os trabalhadores já sofrem com o adoecimento e pressupõe-se que a tendência seja o agravamento da situação.

\section{Considerações Finais}

Os resultados desta investigação, apresentados e discutidos anteriormente, permitem apontar algumas conclusões gerais, que estão aqui elaboradas sob dois pontos de vista: o primeiro referente aos trabalhadores, e o segundo, referente à empresa.

Na psicodinâmica dos vendedores participantes há predomínio de sofrimento, que se relaciona, basicamente, ao ressentimento por não serem reconhecidos, ao cansaço devido a múltiplos fatores, mas principalmente à pressão no trabalho, à ambiguidade na relação com a chefia e ao medo e à desconfiança relativos à chefia, aos colegas e à própria empresa.

A atividade dos trabalhadores é notadamente marcada por controle rígido, falta de espaço para discussão ou negociação, ritmo de trabalho acelerado, prazos extremamente inflexíveis, o que não permite um espaço de convivência na organização, impossibilitando a formação de um coletivo de trabalho e também da elaboração de emoções e experiências.

O sofrimento experimentado, consequência da organização do trabalho rígida e inflexível e do quase inexistente espaço para a fala, parece ter passado por um momento no qual os vendedores conseguiam tecer e manter seus mecanismos de defesa. Entretanto, em função do conteúdo das entrevistas, supõe-se que mesmo as defesas estejam perdendo a funcionalidade, culminando num contexto marcado pelo adoecimento coletivo dos empregados, ao menos no setor de vendas.
Evidentemente, essa situação é delicada e dolorosa para os trabalhadores, que sofrem prejuízos imediatos. Todavia, é nociva também para a empresa, na medida em que índices de rotatividade e absenteísmo aumentam, enquanto índices de produtividade tendem a cair consideravelmente. Via de regra, a produtividade é consequência da saúde e do prazer no trabalho, e pode ser efetivamente incrementada somente se os trabalhadores encontram-se cuidados e preservados.

Nesse sentido, para a empresa, recomenda-se a adoção de medidas que visem efetivamente melhorar o ambiente de trabalho, o que pode ser feito a partir da demanda e da fala do trabalhador. Não se pode, para fins de melhoria da organização do trabalho, pressupor necessidades dos indivíduos e promover qualquer tipo de ação: necessita-se de ações concretas, agudas, que atinjam de forma certeira os problemas. No caso, essas medidas devem ser adotadas levando em consideração a opinião e as experiências cotidianas dos funcionários, implicados no processo de vender e por isso mesmo donos de um saber fazer que precisa ser considerado na hora de estabelecer regras, prazos e metas.

De maneira concreta, a empresa pode aumentar o quadro de funcionários ou, na impossibilidade, ao menos rever a distribuição de tarefas. Outra estratégia seria implantar um setor de gestão de pessoas que pudesse acompanhar a atividade dos empregados e analisar a lógica das exigências e metas.

Recomenda-se, mais que isso, uma profunda revisão no significado do trabalhador para essa organização. Mesmo dentro de um contexto capitalista, é possível o cuidado com os funcionários, oferecendo aos mesmos, condições de trabalho dignas e tratando-os, não como meras engrenagens de uma máquina, e sim como sujeitos no seu trabalho.

Espera-se que as contribuições deste estudo possam ser de utilidade para outros pesquisadores que desejem compreender e trabalhar em prol da saúde psíquica do trabalhador e, consequentemente, de melhores condições de trabalho.

\section{Referências}

Antunes, R. (1998). Adeus ao trabalho? Ensaio sobre as metamorfoses e a centralidade do mundo do trabalho. Campinas: Cortez.

Antunes, R. (2000). Os sentidos do trabalho: ensaio sobre a afirmação e a negação do trabalho. São Paulo: Boitempo.

Bardin, L. (1977). Análise de conteúdo. Lisboa: Edições 70.

Bernhoeft, R. (1999). Desafios e oportunidades das sociedades brasileiras. Em I.G. S. Martins, P. L. Menezes \& R. Bernhoeft (Org.), Empresas familiares brasileiras: perfil e perspectivas (pp. 25-49). São Paulo: Negócio.

Dejours, C. (1987). Plaisir et souffrance dans lês travail. Paris: Centre National de la Recherche Scientifique.

Dejours, C. (1993a). Travail: Usure mental, Vol. 1. Paris: Bayard.

Dejours, C. (1993b). A loucura do trabalho: estudo de psicopatologia do trabalho (M. L. S. Betiol, Trad.). São Paulo: Cortez (Trabalho original publicado em 1987).

Dejours, C. (1999a). O fator humano (M. L. S. Betiol, Trad.). Rio de Janeiro: FGV (Trabalho original publicado em 1997). 
Dejours, C. (1999b). A banalização da injustiça social (L. A Monjardim, Trad.). Rio de Janeiro: Editora FGV (Trabalho original publicado em 1998).

Dejours, C. (1999c). Conferências brasileiras: identidade, reconhecimento e transgressão no trabalho (A. C. F. Reis, Trad.). São Paulo: Fundap, EAES/ FGV (Trabalho original publicado em 1999).

Dejours, C. (2001a). Violence et travail. Le Corrier, 1, 2-16. Retirado em 10/08/01, de http://www.paris-nord-sftg.com/ cr.violence.travail.0104.htm.

Dejours, C. (2001b). La domination simbolyque. Sciences économiques et sociales en Île-de-France à Versailles, 6, 13-21. Retirado em 20/01/01, de http://www.acversailles.fr/pedagogi/ses/ vieses/hodebas/dejours24-10-00.htm

Dejours, C. (2001c). La guerre économique n'aura pas lieu. Sciences économiques et sociales en Île-de-France à Versailles, 5, 7-13. Retirado em 20/01/01, de http://www.ac-versailles.fr/ pedagogi/ses/vie-ses/ hodebas/dejours16-05-00.htm.

Dejours, C. (2001d). Le mal-vivre ensemble. Sciences économiques et sociales en Île-de-France à Versailles, 7, 3-09. Retirado em 20/01/01, de http://www.ac-versailles.fr/pedagogi/ses/ vieses/hodebas/dejours16-01-01.htm.

Dejours, C., \& Abdoucheli, E (1990). Intinéraire théorique en psychopathologie du travail. Revue Prevenir, 20, 21-38.

Dejours, C., Abdoucheli, E., \& Jayet, C. (1994). Psicodinâmica do trabalho: contribuições da escola dejouriana à análise da relação prazer, sofrimento e trabalho (M. I. S. Betiol, Trad). São Paulo: Atlas.

Derrienic, F., \& Vézina, M. (2000). Organisation du travail et santé mentale: approches épidemiologiques. Revue Internationale de Psychopathologie et de Psychodynamique du travail, 5, 7-22.

Enriquez, E. (2000). O indivíduo preso na armadilha da estrutura estratégica. Em F. C. P. Motta \& M. E. Freitas (Orgs.), Vida psíquica e organização (pp. 16-35). Rio de Janeiro: FGV.

Ferreira, M. C., \& Mendes, A. M. (2001). "Só de pensar em trabalhar, já fico de mau humor": atividade de atendimento ao público e prazer-sofrimento no trabalho. Estudos de Psicologia, 6, 93-104.

Jayet, C. (1994). Psycodynamique du travail au quotidian. Paris: AleXitére.

Linhares, N. J. R. (1994). Atividade, prazer-sofrimento e estratégias defensivas do enfermeiro: um estudo na UTI de um hospital público-DF. Dissertação de Mestrado, Universidade de Brasília, Brasília.

Mendes, A. M. (1994). Prazer-sofrimento no trabalho qualificado: um estudo exploratório com engenheiros de uma empresa pública de telecomunicações. Dissertação de Mestrado, Universidade de Brasília, Brasília.
Mendes, A. M. (1995). Os novos paradigmas de organização do trabalho: implicações na saúde mental dos trabalhadores. Revista Brasileira de Saúde Ocupacional, 85/86, 55-60.

Mendes, A. M. (1996). Comportamento defensivo: uma estratégia para suportar o sofrimento no trabalho. Revista de Psicologia, 14(1), 27-32.

Mendes, A. M. (2004). Cultura organizacional e prazersofrimento no trabalho: uma abordagem psicodinâmica. Em A. Tamayo (Org.), Cultura e saúde nas organizações (pp. 53-69). São Paulo: Artmed.

Mendes, A. M. (2007). Da Psicodinâmica à Psicopatologia do Trabalho. Em A. M. Mendes (Org.), Psicodinâmica do trabalho: teoria, método e pesquisas (pp. 07-16). São Paulo: Casa do Psicólogo.

Mendes, A. M., \& Morrone, C. F. (2002). Vivências de prazersofrimento e saúde psíquica no trabalho: trajetória conceitual e empírica. Em A. M. Mendes, L. O. Borges \& M. C. Ferreira (Orgs.), Trabalho em transição, saúde em risco (pp. 42-57). Brasília: UnB.

Mendes, A. M., \& Linhares, N. J. R. (1996). A defesa como uma estratégia frente ao sofrimento no trabalho: um estudo com enfermeiros de UTI. Revista Brasileira de Enfermagem, 49(2), $267-280$.

Montgomery, N., \& Amaral, A. C. R. (1999). Atribuições do Conselho de Administração: novas formas de gestão corporativa. Em I. G. S. Martins, P. L. Menezes \& R. Bernhoeft (Orgs.), Empresas familiares brasileiras: perfil e perspectivas (pp. 77-93). São Paulo: Negócio.

Morin, E. (2002). Os sentidos do trabalho. Em T. Wood Jr. (Org.), Gestão de pessoas: o fator humano (pp. 12-23). São Paulo: Atlas.

Morrone, C. F. (2001). "Só para não ficar desempregado" - Resignificando o sofrimento psíquico no trabalho: estudo com trabalhadores em atividades informais. Dissertação de Mestrado, Universidade de Brasília, Brasília.

Rebouças de Oliveira, D. (1999). Empresa familiar: Como fortalecer o empreendimento e otimizar o processo sucessório. São Paulo: Atlas. 